Tropical Journal of Pharmaceutical Research, June 2008; 7 (2): 981-986

(C) Pharmacotherapy Group, Faculty of Pharmacy, University of Benin,

Benin City, Nigeria.

All rights reserved.

Research Article

Available online at http://www.tjpr.org

\title{
Estimation of the release profiles of multi-unit dose tablets of theophylline from the release profiles of their components
}

\author{
MU Uhumwangho* and RS Okor \\ Department of Pharmaceutics and Pharmaceutics Technology, University of Benin, Benin City, Nigeria
}

\begin{abstract}
Purpose: The objective of this study is to investigate whether the drug release profile of a multi-unit dose form consisting of fast and slow release components can be predicted from the release profiles of their components by simple summation.

Method: The fast release component consisted of conventional granules of theophylline made by wet massing the drug powder with starch mucilage $(20 \% \mathrm{w} / \mathrm{v})$. The slow release component consisted of matrix granules of the drug made by triturating the drug powder with melted carnuba wax (i.e. melt granulation). Each type of granules was compressed to tablets of weight 100,150 or $200 \mathrm{mg}$. To form the multi-unit dosage tablets of drug content $300 \mathrm{mg}$ each, the conventional and matrix granules were mixed in the ratio 1:2, 1:1 and 2:1, and compressed. The tablets were subjected to dissolution test and from the experimental release curve the prompt release $\left(m_{p}\right)$ in the first $1 \mathrm{~h}$, the maximum release $\left(m_{\infty}\right)$ and the time to attain it $\left(t_{\infty}\right)$ were obtained.

Result: For a given composition of the multi-unit dose tablets, the theoretical release curve was obtained by summation of the release from each component at the different time intervals. The $m_{p}$ values of the theoretically estimated release curves were generally higher, while their $t_{\infty}$ values were generally shorter than the corresponding values for the experimental curves.

Conclusion: The indication is that drug release from the multi-unit dose tablets was more retarded than could be theoretically estimated. Apparently, the two components interfere with each other's release.
\end{abstract}

Keywords: single-unit and multi-unit dose forms, release profiles, theophylline

*Corresponding Author: Email: mike2003u@yahoo.com or uhumwangho@uniben.edu Tel: +234-8052057767 


\section{INTRODUCTION}

Single (unit) dosage forms usually consist of drug particles of same release profile while a multi-unit dosage system consists of particles (units) of different drug or same drug particles but of differing release profiles with respect to onset, rate and the maximum release, etc ${ }^{1,2}$. Capsules or tablets can be used either as single unit or multi-unit dosage forms for controlled release applications by formulating them with special excipients ${ }^{3,4}$. Multiple-unit dosage forms offer advantages over the single-unit systems ${ }^{1}$ by producing an initial prompt release followed by a sustained release to prolong the initial therapeutic effect, thus obviating the need for repeat dosage. The release rate of drug particles may be retarded by a process of melt granulation whereby the drug powder is triturated with a melted wax to form matrix granules which do not disintegrate to their primary (powder) particles upon contact with aqueous fluid ${ }^{5}$.

A recent study ${ }^{6}$ showed that tableting rather than encapsulation of the matrix particles is more effective in prolonging the release of the test drug. Hence, the present study focused on the tablet formulation only. In that study, multi-unit tablets of theophylline were formulated by mixing conventional and matrix granules of the drug in various proportions.

The objective of the present study was to investigate whether the release profile of the multi-unit dose tablets can be predicted from the known profiles of the individual components that make up the multi-unit system. Theophylline was considered a candidate for the multi-unit dose formulation because it is indicated for the treatment of chronic asthma requiring prolonged medication.

\section{MATERIALS AND METHODS}

Carnuba wax (Halewood Chemicals Ltd, England) is a fine waxy solid with melting point of $82-88^{\circ} \mathrm{C}$, yellowish in colour and was used as the matrix former. Maize starch $(B D H$, Chemical, Poole, UK) was used as binder in the form of mucilage $(20 \% \mathrm{w} / \mathrm{v})$ and as a disintegrant in the form of a dried powder (5
$\% w / w)$ in the tablets, while magnesium stearate (Sakai Chem Co, Japan) was used as lubricant at a concentration of $0.5 \% \mathrm{w} / \mathrm{w}$ in the tablet formulations. The test drug theophylline (Sigma Chemical Company, St Louis, MO) was a gift from Vitaboitics Nigeria Ltd.

\section{METHODS}

Melt and conventional granulation

techniques: The method earlier described ${ }^{7}$ was followed. In the procedure the wax material $(20 \mathrm{~g})$ was melted in a stainless steel container in a water bath at $90^{\circ} \mathrm{C}$. A sample $(100 \mathrm{~g})$ of the theophylline powder (melting point $270-274^{\circ} \mathrm{C}$ ) was then added to the molten wax and mixed well with a Kenwood mixer (model A901P England) for 5mins. The theophylline was therefore thermally stable at the melting point of the wax. The mixture was allowed to cool at room temperature for $1 \mathrm{~h}$ and then pressed through a sieve of aperture size; $710 \mu \mathrm{m}$ and dried in a vacuum oven (model A2904, Gallenkamp, England) at $25^{\circ} \mathrm{C}$ for $1 \mathrm{~h}$ to produce matrix granules that will not disintegrate in aqueous fluid to their primary (powder) particles ${ }^{5}$. Conventional granules of theophylline were produced by wet -massing a sample of the theophylline powder $(100 \mathrm{~g})$ with $20 \% \mathrm{w} / \mathrm{v}$ starch mucilage $(38 \mathrm{ml})$. The wetmass was screened and dried in a vacuum oven at $25^{\circ} \mathrm{C}$ for $1 \mathrm{~h}$. Moisture content was analysed with a moisture analyzer (Denward Instruments Ltd, UK) and were $2.4 \pm 1.1 \% \mathrm{w} / \mathrm{w}$ (conventional) and $2.2 \pm 1.1 \% \mathrm{w} / \mathrm{w}$ (melt granulation).

\section{Formulation of multi-unit dosage forms} The conventional $(A)$ and the matrix granules (B) were mixed together in different proportions in the ratios $(A: B) 2: 1,1: 1,1: 2$ (Table 1). In each mixture, aliquots of the granules were selected such that the total drug content in a tablet was $300 \mathrm{mg}$. The conventional and the matrix granules, or their admixtures were compressed using a single punch tableting machine (Manesty Type $\mathrm{F}_{3}$, Poole, England) at a constant load (30 arbitrary units on the load scale) to form flat faced tablets of diameter $12.5 \mathrm{~mm}$. The 
Uhumwangho \& Okor

Table 1: Formulation of the single-unit and multi-unit dose tablets

\begin{tabular}{|c|c|c|c|}
\hline \multicolumn{4}{|c|}{ Amount (mg) of drug per tablet: } \\
\hline \multirow{2}{*}{$\begin{array}{l}\text { Single unit dose } \\
\text { tablets } \\
\mathrm{A}(\mathrm{mg})\end{array}$} & \multicolumn{2}{|c|}{$\begin{array}{l}\text { multi-unit dose } \\
\text { tablets }\end{array}$} & \multirow{2}{*}{$\begin{array}{l}\text { Ratio } \\
\text { A:B }\end{array}$} \\
\hline & $\mathrm{B}(\mathrm{mg})$ & $A+B(m g)$ & \\
\hline 100 & 200 & 300 & $1: 2$ \\
\hline 150 & 150 & 300 & $1: 1$ \\
\hline 200 & 100 & 300 & $2: 1$ \\
\hline
\end{tabular}

Table 2: Release parameters of tablets of the single-unit tablets of the conventional (A) and the matrix granules (B)

\begin{tabular}{ccccc}
\hline $\begin{array}{c}\text { Drug load per } \\
\text { tablet } \\
(\mathbf{m g})\end{array}$ & \multicolumn{2}{c}{$\mathrm{A}$} & \multicolumn{2}{c}{$\mathrm{B}$} \\
\hline 100 & $\mathrm{~m}_{\infty(\mathrm{mg})}$ & $\mathrm{t}_{\infty(\mathrm{h})}$ & $\mathrm{m}_{\infty(\mathrm{mg})}$ & $\mathrm{t}_{\infty(\mathrm{h})}$ \\
150 & 190 & 3 & 192 & 5 \\
200 & 290 & 3 & 284 & 6 \\
\hline
\end{tabular}

Note: Two tablets were used in each dissolution test

Table 3: A comparison of the empirical and theoretical release parameters for the multi-unit dose tablets

\begin{tabular}{|c|c|c|c|c|c|c|}
\hline \multirow[t]{3}{*}{ Evaluation parameters } & \multicolumn{6}{|c|}{$\begin{array}{l}\text { Formulation of the multi-unit dose tablets, ratio } \\
\qquad A: B\end{array}$} \\
\hline & \multicolumn{2}{|c|}{$1: 2$} & \multicolumn{2}{|c|}{$1: 1$} & \multicolumn{2}{|c|}{$2: 1$} \\
\hline & E & $\mathbf{T}$ & E & $\mathbf{T}$ & E & $\mathbf{T}$ \\
\hline$m_{\infty}(m g)$ & 578 & 584 & 580 & 574 & 584 & 580 \\
\hline$m_{p}$ & 128 & 198 & 180 & 280 & 240 & 428 \\
\hline$t_{\infty}(h)$ & 12 & 8 & 11 & 6 & 9 & 5 \\
\hline
\end{tabular}

Note: $E=$ empirical and $T=$ theoretical

weights of the tablets varied depending on the formulation but the targeted drug content was $300 \mathrm{mg}$ each. In another aspect of the study, tablets of $A$ or $B$ only with varied drug content 100,150 and $200 \mathrm{mg}$ were also formed. In each case magnesium stearate $(0.5 \% \mathrm{w} / \mathrm{w})$ and dried maize starch powder $(5 \% \mathrm{w} / \mathrm{w})$ were added to the granules prior to compression. The tablets were allowed to equilibrate in a dessicator, $24 \mathrm{~h}$ before their evaluation.

Dissolution test: The method described previously by Okor et $\mathrm{al}^{8}$ was followed. Two tablets were placed in a cylindrical basket (aperture size $425 \mu \mathrm{m}$ : diameter $20 \mathrm{~mm}$; height $30 \mathrm{~mm}$ ), which was immersed in $800 \mathrm{ml}$ of leaching fluid $(0.1 \mathrm{~N}$ hydrochloric acid maintained at $37 \pm 2^{\circ} \mathrm{C}$ ). The fluid was stirred at $100 \mathrm{rpm}$ with a single blade GallenKamp stirrer (Model APP No 4B 5784A. Cat No: SS530). Samples of the leaching fluid $(5 \mathrm{ml})$ were withdrawn at selected time intervals with a pipette fitted with a cotton wool plug and replaced with an equal volume of drug-free dissolution fluid. The samples were suitably diluted with blank dissolution fluid and were analysed for content of theophylline 
A

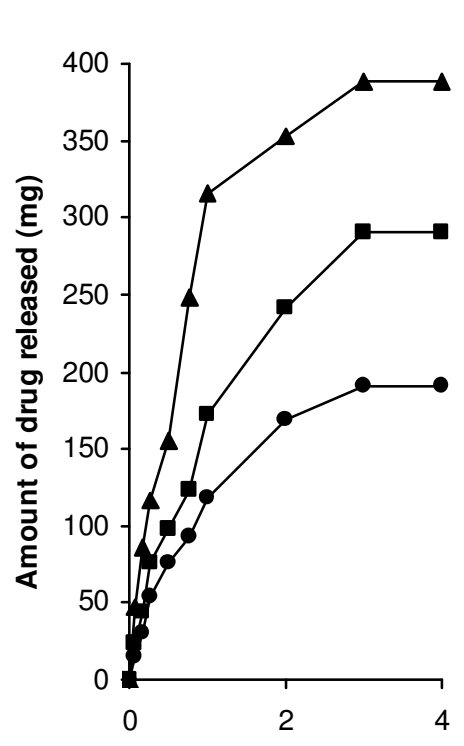

B

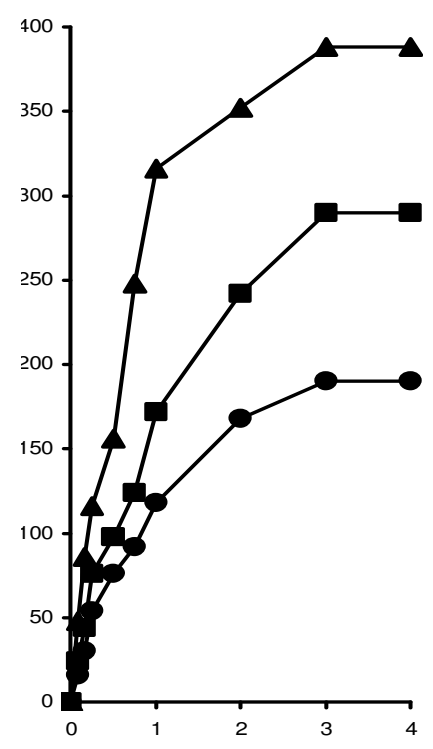

Time (h)

Fig 1: Release profiles of the single-unit tablets of the conventional $(A)$ and matrix granules (B). The drug loading $(\mathrm{mg})$ in each of the tablets are indicated on the curves.

$1: 2$

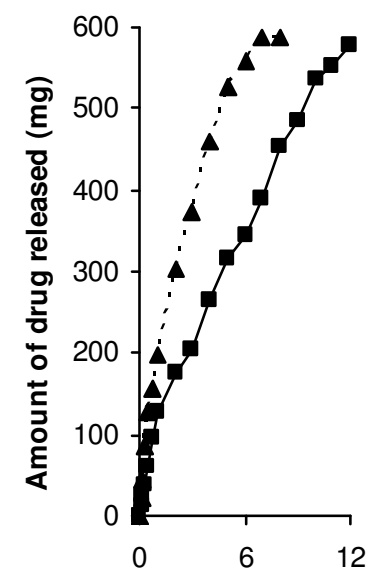

$1: 1$

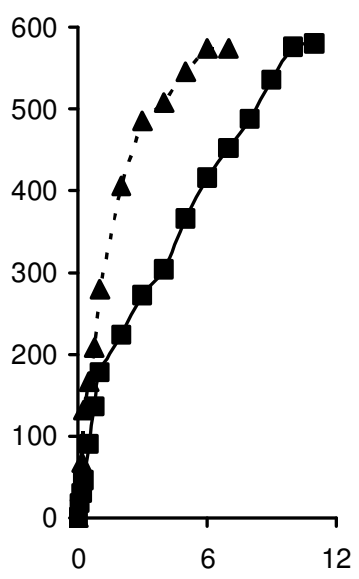

$2: 1$

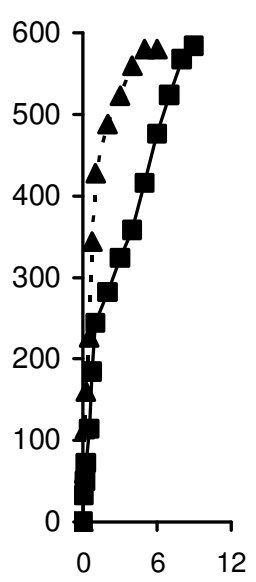

Time (h)

Fig 2: Release profiles of the multi-unit dose tablets showing theoretical (.. $\mathbf{\Delta} .$.$) and the$ empirical release $(\mathbf{m})$ release curves of the different formulations

spectrophotometrically at $\lambda_{\max }, \quad 272 \mathrm{~nm}$ (Spectronic 21D, Bausch and Lomb, USA). The samples were filtered using No. 1
Whatmann filter paper before assay. The amounts released were expressed as a percentage of the initial amount of drug in the 
A

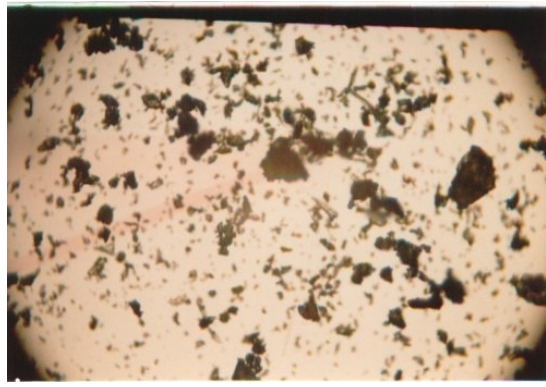

B

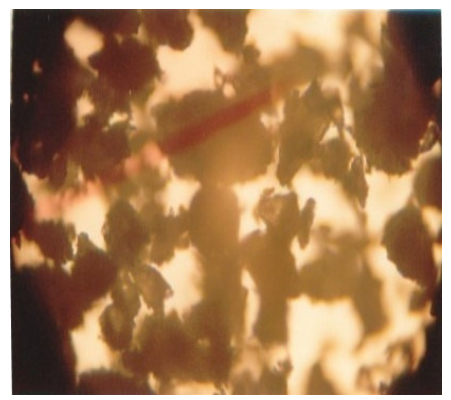

Fig 3: Photomicrograph $(\times 40)$ of drug particles resulting from disintegration of the single-unit tablets of the conventional $(A)$ or matrix granules $(B)$

capsule or tablet. The dissolution test was carried out in quadruplicate and the mean results reported. Individual results were reproducible to $\pm 10 \%$ of the mean. The release data were subjected to student t test $p>0.05$ to test for significance of difference between paired data.

Estimation of the theoretical release curves: The theoretical release curves for the multi-unit dose tablets comprising of two components ( $A$ and $B$ ) were obtained by summation of the individual release from $A$ and $B$ at a given time interval. Thus, if the release from $A$ at $1 \mathrm{~h}$ point was $172 \mathrm{mg}$ and that from $B$ was $108 \mathrm{mg}$, the estimated release for the multiunit dose tablet at $1 \mathrm{~h}$ point will be $172 \mathrm{mg}+108 \mathrm{mg}=280 \mathrm{mg}$.

\section{RESULTS}

Dissolution profiles of the single unit tablets: The data are presented in Fig 1. Expectedly, the tablets of the conventional granules gave a faster release as reflected by their shorter $t_{\infty}$ values (3h) compared with those of tablets of the matrix granules (5 to 8h) (Table 2).

\section{Dissolution profiles of the multi-unit dose tablets}

The empirical and the theoretically estimated release curves are presented in Fig 2 . The empirical release was more retarded than was theoretically estimated. This is reflected by the differences in the $m_{p}$ and $t_{\infty}$ values (Table 3 ) obtained from the empirical and the theoretical release curves. The empirical $m_{p}$ values were general lower while their $t_{\infty}$ values were generally longer than the corresponding values for the theoretical release curves. The difference was up to $56 \%$ ( $m_{p}$ values) and $45 \%$ ( $\mathrm{t}_{\infty}$ values).

\section{DISCUSSION}

The slow release from tablets of matrix granules is attributable to the hydrophobic nature of the carnuba wax, which was used as the matrix former. Besides, the tablets of the matrix granules disintegrated to larger particles compared with the particles resulting from disintegration of the conventional tablets (Fig 3). Hence, the matrix particles exposed a lower surface area for the dissolution. This point was made earlier to the effect that the matrix granules unlike the conventional granules would not in turn disintegrate to their primary (powder) particles ${ }^{5}$.

The observation that the release from the multi-unit dose tablets was slower than theoretically estimated from the profiles of individual components indicates that the components in the multi-unit dose tablets affected each other's release. Presumably, the release of one component into the dissolution medium would alter the concentration gradient for mass transfer from the other component. For instance, the rapid dissolution of drug from the conventional granules into the dissolution medium would be expected to lower the concentration gradient 
for mass transfer from the matrix granules, or vice versa

\section{CONCLUSION}

The indication is that the release profile of a multi-unit dosage form cannot readily be deduced from the individual profiles of its components. Hence, the optimal formulation of the multi-unit dosage form that would give the desired release profile must be experimentally determined.

\section{ACKNOWLEDGEMENT}

Dr MU Uhumwangho is highly grateful to University of Benin Research and Publication Committee (URPC) for the grant award (Ref No. REG/ER/URPC/SS.1). The authors wish to thank Vitabiotics Nigeria Limited for providing theophylline powder used in the research.

\section{REFERENCES}

1. Vial-Bernasconi AC, Doelker E, Buri P. Prolonged release capsules: divided and monolithic forms. STP Pharma Sci. 1988; 4: 397-409.

2. Follonier N, Doelker E. Biopharmaceutical comparison of oral multiple-unit and single-unit sustainedrelease dosage forms. STP Pharma Sci. 1992; 2:141-155.
3. Ojantakanen S. Effect of viscosity grade of polymer additive and compression force on release of ibuprofen from hard gelatin capsules. Acta Pharm. Fenn. 1992; 101: 119-126.

4. Digenis GA. The invivo behavior of multiparticulate versus single unit dosage formulations. In: Ghebre-Sellassie I (ed),. Multiparticulate Oral Drug Delivery. Maecel Dekker, Inc New York, USA, 1994 pp 333-335.

5. Uhumwangho MU, Okor RS. Studies on the compressibility of wax matrix granules of acetaminophen and their admixtures with various tableting bases. Pak J Pharm. Sci. 2006; 19: 103-107.

6. Uhumwangho $M U$, Okor RS. Multi-unit dosage formulations of theophylline for controlled release applications. Acta Pol Pharm. 2007; 64: 553-559.

7. Uhumwangho MU, Okor R.S, Eichie F.E, Azu H, Onyebuchi $A E$. Incorporation of certain hydrophobic excipients in the core of melt granules of paracetamol and the effect on drug release profiles. Trop J Pharm Res. 2007; 6: $767-771$.

8. Okor RS, Otimenyin S, ljeh I. Coating of certain matrix cores with aqueous - based systems of acrylate methacrylate, a water - soluble copolymer and drug release profiles. J. Control. Rel. 1991; 16: $344-354$. 